\title{
Operational validation of HYDRUS (2D/3D) for capillary barriers using data of a 10-m tipping trough
}

\author{
Klaus Berger \\ University of Hamburg, Institute of Soil Science, Allende-Platz 2, 20146 Hamburg, Germany. \\ Tel.: +49 4042838 2006. Fax: +49 4042838 2024. E-mail: klaus.berger@uni-hamburg.de
}

\begin{abstract}
Capillary barriers are an interesting alternative component for cover systems of landfills and contaminated sites. Provided they are sufficiently validated, soil hydrological models could be fast and powerful tools for the dimensioning of capillary barriers. Outflow rates measured in a $10 \mathrm{~m}$ long tipping trough for one material combination and two slopes from stationary periods were compared to simulation results of HYDRUS (2D/3D), Version 2.05. The measured outflow rates show a typical pattern with slope-dependent threshold values indicating the efficiency of the capillary barrier. This flow pattern could not be reproduced with HYDRUS (2D/3D) that for different input setups produced smooth patterns without thresholds. The input setup was varied for different soil hydraulic models (van Genuchten-Mualem vs. Brooks-Corey), homogeneous and heterogeneous transport domains (no scaling vs. stochastically distributed scaling factors considering the Miller-Miller similitude), different HYDRUS versions (standard vs. alternative; i.e., with material properties assigned either to finite element nodes or finite elements, respectively), and different lower boundary conditions (seepage face vs. free drainage). Differences between measured and simulated outflow patterns could be caused by the measurements, the application of the model, or by the model itself. The van Genuchten-Mualem model may not be suitable to describe the soil hydrological relationships of these particular materials. The reason for the mismatch, however, could not be identified yet.
\end{abstract}

Keywords: Capillary barriers; Funneled flow; Landfills; Cover systems; Operational validation; HYDRUS (2D/3D).

\section{INTRODUCTION}

Capillary barriers are two-layer systems consisting of an upper layer made of a relatively fine-grained and fine-porous material (e.g., sand), the so-called 'capillary layer', underlain by a lower layer made of a relatively coarse-grained and coarseporous material (e.g., gravel), the so-called 'capillary block'. There is a sharp interface between the two layers that is sloped. Water percolating through a capillary layer under unsaturated conditions is held at the interface due to capillary forces (a capillary barrier effect). When inflow into the capillary layer is relatively small, nearly no water breaks through the interface into the capillary block. Instead, water moves laterally in the capillary layer along the interface (a wick[ing] effect or a capillary diversion) (see, e.g., Oldenburg and Pruess, 1993; Yeh et al., 1994). This type of flow is called 'funneled flow' (Kung 1990; illustrated using the dye tracer experiment depicted in Figure 1). However, when inflow into the capillary layer becomes higher, water begins to break through the interface. As inflow decreases, breakthrough decreases as well and the capillary barrier 'recovers'.

Capillary barriers are not only a curious soil hydrological phenomenon, but they also represent an interesting component in cover systems for landfills and contaminated sites. Cover systems are multi-layer systems consisting of layers that perform specific tasks. Especially on steep slopes, capillary barriers can be used as a stand-alone barrier or as a component of a liner that is overlain by a compacted cohesive layer or a geomembrane for limiting inflow into the capillary layer.

For the use in cover systems, capillary barriers have to be dimensioned. This means that suitable material combinations of the capillary layer and capillary block, and a suitable maximum distance to a drain that removes water from the system have to be determined depending on site-specific conditions. The following parameters are relevant:

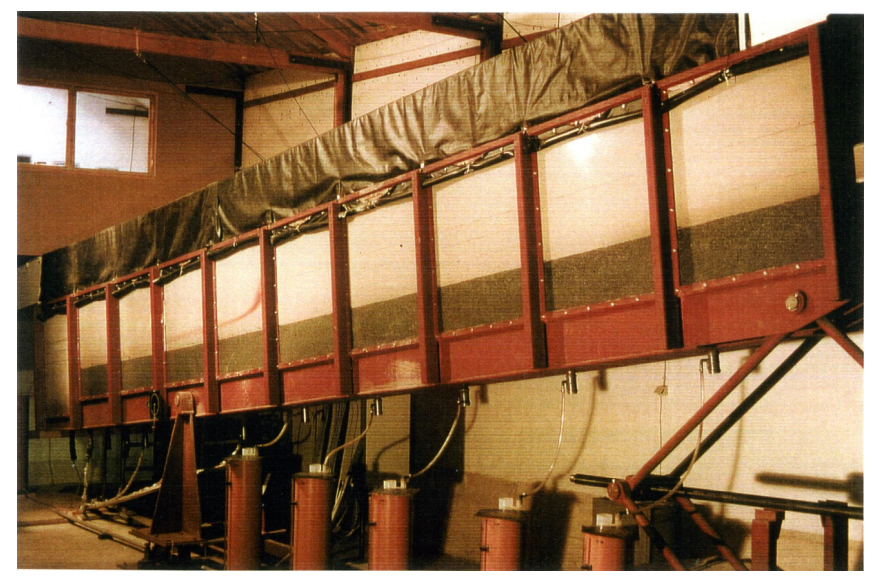

Fig. 1. A front view of the filled 10-m tipping trough (dark brown material = capillary block, light-colored material = capillary layer, and collection sump in the left-most segment). A dye tracer experiment with a red tracer is depicted on the left side. The irrigation system is inside the black box on the top of the tipping trough. Photo: Institute of Soil Science, University of Hamburg.

1. Soil hydrological properties of the materials of the capillary layer and the capillary block;

2. Slope;

3. Slope length / maximum distance to the drain;

4. Shape of the slope (convex - concave; convergent divergent);

5. Infiltration rate into the capillary layer. This depends on the climate of the site and the layers above the capillary barrier.

There are several principal methods available to dimension capillary barriers with specific advantages and disadvantages. Table 1 gives an overview of the most important methods. Several empirical investigations with large test fields (lysimeters) 
Table 1. Important principle methods for dimensioning capillary barriers and their advantages and disadvantages.

\begin{tabular}{|c|c|}
\hline$I$. & Empirical investigations with large test fields (lysimeters) \\
\hline Advantages: & Close to reality due to field size \\
\hline Disadvantages: & $\begin{array}{l}\text { Limited to very few parameter values and material combinations } \\
\text { Requires experience and accuracy to avoid systematic errors } \\
\text { Time-consuming (many years) } \\
\text { Very expensive } \\
\text { Measurement results depend on the weather as a boundary condition } \\
\text { and are therefore not reproducible }\end{array}$ \\
\hline II. & $\begin{array}{l}\text { Empirical investigations with tipping troughs (tilt gutters) in pilot } \\
\text { plant scale }\end{array}$ \\
\hline Advantages: & $\begin{array}{l}\text { Relatively close to the reality in the field } \\
\text { Measurement results are (approximately) reproducible }\end{array}$ \\
\hline Disadvantages: & $\begin{array}{l}\text { Limited to some parameter values and material combinations } \\
\text { Relatively time-consuming (many months) } \\
\text { Expensive }\end{array}$ \\
\hline III. & Simulations with 2D or 3D models \\
\hline Advantages: & $\begin{array}{l}\text { Allows analyzing many parameter values and material combinations } \\
\text { Fast } \\
\text { Low costs }\end{array}$ \\
\hline Disadvantages: & $\begin{array}{l}\text { Simulation results are reproducible } \\
\text { Requires sufficient validation of the model for a particular type of } \\
\text { application }\end{array}$ \\
\hline
\end{tabular}

were performed in Germany, for example, on the landfill Georgswerder in Hamburg, which had six test fields, each $50 \mathrm{~m}$ long and $10 \mathrm{~m}$ wide, one having a capillary barrier below a compacted cohesive layer (Melchior, 1993; Melchior et al., 2010). Other test fields in Germany with capillary barrier were operated on the landfills 'Am Stempel' near Marburg and 'Monte Scherbelino' near Frankfurt am Main (Jelinek, 1997), and in Karlsruhe (Zischak, 1997). Further test fields were operated but are mostly only documented in German (overviews of these test fields can be found in Steinert (1999) and Pfeiffer (2006)).

Tipping troughs on a pilot plant scale of capillary barriers existed in Germany at the University of Hamburg (length $\mathrm{x}$ depth $\times$ height of $10.0 \mathrm{~m} \times 0.5 \mathrm{~m} \times 1.0 \mathrm{~m}$; Steinert, 1999; Steinert et al., 1997a,b), the Technical University of Darmstadt (2 troughs with L x D x H of $8.0 \mathrm{~m} \times 0.2 \mathrm{~m} \times 1.5 \mathrm{~m}$; Holfelder, 2002; Kämpf, 2000; Kämpf et al., 2003; von der Hude, 1999), the Technical University of Munich (L x D x H of $6.0 \mathrm{~m}$ x 0.6 $\mathrm{m} \times 1.0 \mathrm{~m}$; Barth 2003), and the University of Giessen (L x D x $\mathrm{H}$ of $6.0 \mathrm{~m} \times 0.6 \mathrm{~m} \times 1.0 \mathrm{~m}$; Pfeiffer, 2006). However, objectives of the research and materials of the capillary barriers were different in these studies, and thus the results are difficult to compare. Furthermore, several tipping troughs on a laboratory scale (approximately $1 \mathrm{~m}$ length) were operated in Germany, e.g., at the University of Hamburg. The results of these small troughs could, however, hardly be transferred to a field scale (Steinert, 1999).

Comparisons of measured and simulated data for tipping troughs were performed in Germany for SWMS 2D (Berger, 2017; Steinert, 1997a,b), for HYDRUS-2D (Kämpf, 2000; Kämpf et al., 2003; Pfeiffer, 2006), and for Feflow 5.0 (Barth, 2003). The authors assessed the success of output comparisons very differently, from 'failure' to 'in principle possible,' 'satisfactory' to 'good'. However, Barth (2003) and Kämpf et al. (2003) especially emphasized the importance of the soil hydraulic properties for the simulation results.

Simulations with two- or three-dimensional models such as HYDRUS (2D/3D) (Radcliffe and Šimůnek, 2010; Šejna et al., 2016; Šimůnek et al., 2016) have major advantages compared to empirical investigations (see Table 1), but require prior validation. This is required for any particular type of application to assure that the simulation results are close to reality and can be transferred into the field. Validation is a complex methodology (Knepell and Arangno, 1993; Konikow and Bredehoft, 1992; Oreskes et al., 1994; see also Berger, 1999). An important aspect of it is operational validation, i.e., comparisons of simulations and measurement results. One such output comparison was performed for HYDRUS (2D/3D), version 2.05 (2.05.0230) (Šejna et al., 2016; Šimůnek et al., 2016), using outflow data of a capillary barrier constructed in a $10 \mathrm{~m}$ long tipping trough (Steinert, 1999). The aim of the simulation was to reproduce measured outflow patterns that describe the efficiency of the capillary barrier.

\section{MATERIAL AND METHODS Experiments with a $10 \mathrm{~m}$ long tipping trough}

Design, experiments, and measurement results with the tipping trough (a tilt gutter) are described in detail in German in Steinert et al. (1997a) and Steinert (1999), and with the first results and more concisely in Steinert et al. (1997b). The following description is focused on information relevant to the simulations discussed below.

The tipping trough (see Figs. 1, 2, and 3) was $10 \mathrm{~m}$ long and $0.5 \mathrm{~m}$ deep. The capillary barrier constructed inside had a height of $1 \mathrm{~m}$ ( $0.3 \mathrm{~m}$ capillary block, $0.7 \mathrm{~m}$ capillary layer). The bottom of the trough was divided into 10 segments by steel panels of $0.15 \mathrm{~m}$ height (for an exception, see below). Each segment was $1 \mathrm{~m}$ long with a separate outflow at the bottom. The capillary barrier was constructed in the upper 9 segments with a central measurement area of $0.3 \mathrm{~m}$ depth and two margins at the front and on the back, each with a depth of $0.1 \mathrm{~m}$, separated by steel panels of $0.15 \mathrm{~m}$ height. The final segment was separated by a $0.3 \mathrm{~m}$ high steel panel and filled with the material of the capillary layer. It served as a collection sump for the capillary layer and had a bottom $0.13 \mathrm{~m}$ below the bottom of the other 9 segments.

The slope of the trough was continuously adjustable up to $1: 3(33 \%)$ by a scissors jack operated by a crank handle. The entire trough stood on weighing cells with a resolution of $1 \mathrm{~kg}$. The empty trough weighed about $4 \mathrm{t}$; the trough filled with materials weighed around $13 \mathrm{t}$, depending on the mass of water in the trough. Outflows were measured with a maximum resolution of 0.11 . An irrigation system on the top of the trough allowed for a uniform irrigation of the entire surface of the capillary layer with a continuously adjustable irrigation rate between 0.1 and $30 \mathrm{~mm} / \mathrm{d}$. A second independent irrigation system was at the end wall.

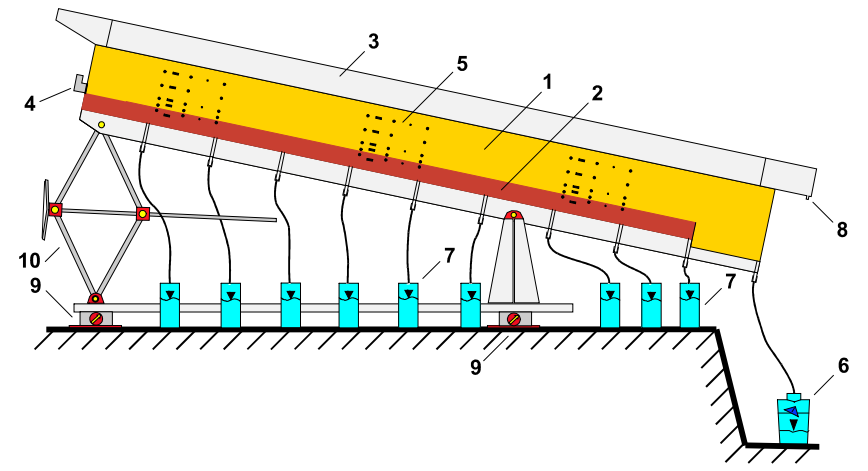

Fig. 2. A schematic side view of the tipping trough at an inclination of 1:5 (1: capillary layer; 2 : capillary block; 3 : cover of the top irrigation system; 4: end wall irrigation system; 5: soil hydrological measurement field; 6 : collection bin of the capillary layer; 7: collection bins of the capillary block; 8: overflow of the top irrigation system; 9: weighing cells; 10: scissors jack with crank handle) (from Steinert (1999), translated into English). (Note: This Figure is side-inverted to Figs. 1 and 3.) 


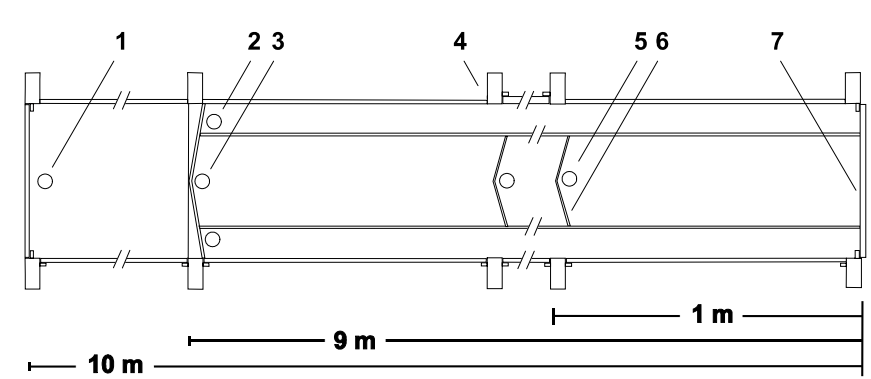

Fig. 3. A schematic top view of the bottom of the tipping trough (1: outflow of the capillary layer/collection sump; 2: outflow of the back margin; 3: central outflow of the $9^{\text {th }}$ capillary block segment; 4: steel bar; 5: central outflow of the $1^{\text {st }}$ capillary block segment; 6 : steel panel; 7: end wall) (from Steinert (1999), translated into English).

The capillary layer was constructed from medium sand. This material originates from the dredged material from the river Elbe that has been treated in a mechanical treatment plant for harbor sediments (called 'METHA'), which is operated by the Hamburg Port Authority. The capillary block consisted of gravel with grain diameters ranging mainly from 1 to $3 \mathrm{~mm}$. Both materials have a narrow particle size distribution.

Experiments with a material combination of the capillary layer and capillary block took several months without interruption. The evaluation was focused on outflow rates from the capillary layer and the capillary block at different inflow rates.

\section{Simulations with HYDRUS (2D/3D)}

Simulations were performed for one material combination, two slopes, and for periods of steady state flow. Two slopes were investigated: a steep slope with 1:5 (20\%) and a flat slope with 1:25 (4\%). Only periods with a constant irrigation rate from the top, no end wall irrigation, and a maximum weighing difference of the entire tipping trough of $5 \mathrm{~kg}$ were simulated. Each period was evaluated in a separate simulation run. The simulation period was set to 34,560 minutes (24 days) to assure steady state at the end of each simulation run. The outflow patterns were characterized by outflow rates from the capillary layer and the capillary block at the end of each simulation run. In the simulations, only outflow from the bottom capillary block segment was simulated, and measured outflows from all 9 capillary block segments of a stationary period were added for comparison. Measured and simulated outflow rates (in dimensions of $\mathrm{L}^{2} / \mathrm{T}$ ) from the capillary layer were reduced, assuming that direct flow is perpendicular from the upper boundary into the final capillary layer segment and thus bypasses the capillary block $(11.4 \%$ of the inflow rate for the slope $1: 5$, and $10.3 \%$ for $1: 25$, respectively). The purpose of this is to reflect only the efficiency of the capillary barrier.

Simulations were performed using a "2D general" HYDRUS geometry in the vertical plane and the units of $\mathrm{cm}$ for length and minutes for time. The finite element (FE) mesh parameters and resulting FE mesh statistics are summarized in Table 2. Mesh refinements were used at the upper and lower boundaries (inflow and outflow) and especially along the interface of the capillary layer and the capillary block, which is a critical zone for the efficiency of the capillary barrier. The upper boundary was assigned a constant flux. The initial condition was set to a constant pressure head of $-50 \mathrm{~cm}$ at each node.

To reproduce the measured outflow patterns of the capillary barrier, the model input setup was varied as summarized in Table 3. In particular:
Table 2. FE mesh parameters (above) and FE mesh statistics (below) used in the numerical simulations. The number of FE nodes and elements generated by HYDRUS with the same FE mesh parameters differ slightly for the two slopes.

\begin{tabular}{l|l}
\hline Targeted FE-size: $5 \mathrm{~cm}$ & Stretching in $\mathrm{x}$-direction: factor 2 \\
\hline Refinements: & FE-size $2.5 \mathrm{~cm}$ \\
$\begin{array}{l}\text { 1. Upper boundary (irrigation) } \\
\begin{array}{l}\text { 2. Lower boundaries (outflows) } \\
\text { 3. Interface of the capillary layer } \\
\text { and capillary block }\end{array}\end{array}$ & FE-size $0.6 \mathrm{~cm}$ \\
\hline
\end{tabular}

\begin{tabular}{l|l|l|l}
\hline Slope & FE nodes & 1D-elements & 2D-elements \\
\hline $1: 5$ & 42513 & 2010 & 84597 \\
\hline $1: 25$ & 42443 & 1917 & 84470 \\
\hline
\end{tabular}

Table 3. Input setup for the numerical simulations.

\begin{tabular}{l|l|l}
\hline & Scenario 1 & Scenario 2 \\
\hline Soil hydraulic model & $\begin{array}{l}\text { van Genuchten- } \\
\text { Mualem }\end{array}$ & Brooks and Corey \\
\hline Homogeneous/Scaling & No scaling & $\begin{array}{l}\text { Stochastically } \\
\text { distributed scaling } \\
\text { factors using the } \\
\text { Miller- Miller } \\
\text { similitude }\end{array}$ \\
\hline HYDRUS version & Standard & Alternative \\
\hline $\begin{array}{l}\text { Lower boundary condition } \\
\text { (Outflow) }\end{array}$ & $\begin{array}{l}\text { Seepage face } \\
\text { (with zero pres- } \\
\text { sure head) }\end{array}$ & Free drainage \\
\hline
\end{tabular}

Soil hydraulic models: Water content-pressure head relationships were measured with a pressure plate apparatus using samples taken in the tipping trough (Steinert et al., 1997a) and evaluated with RETC (van Genuchten et al., 1991) (see Table 4, which also includes the measured saturated hydraulic conductivities, and Fig. 4). The parameters of the van GenuchtenMualem model were already used in earlier simulations with SWMS_2D (Steinert et al., 1997a). Sometimes, coarse materials can $\bar{b}$ e better described using the Brooks and Corey model.

Table 4. Soil hydrological parameters of METHA-sand and 1/3 gravel in the van Genuchten-Mualem model (above) and the Brooks and Corey model (below).

\begin{tabular}{l|l|l|l}
\hline $\begin{array}{l}\text { METHA-sand } \\
r^{2}=0.996\end{array}$ & Mean & \multicolumn{2}{|l}{$95 \%$ confidence interval } \\
\hline$\alpha\left(\mathrm{cm}^{-1}\right)$ & 0.0302 & 0.0283 & 0.0321 \\
$n(-)$ & 5.11 & 4.28 & 5.95 \\
\hline$\theta_{s}(-)$ & 0.3056 & - & - \\
$\theta_{r}(-)$ & 0.0400 & - & - \\
\hline$k_{s}\left(\mathrm{~m} \mathrm{~s}^{-1}\right)$ & $1.3 \mathrm{e}-4$ & - & - \\
$k_{s}\left(\mathrm{~cm} \mathrm{~min}^{-1}\right)$ & 0.78 & & \\
\hline $1 / 3 \mathrm{gravel}^{2}$ & & & \\
$r^{2}=0.998$ & & & \\
\hline$\alpha\left(\mathrm{cm}^{-1}\right)$ & 0.206 & 0.197 & 0.214 \\
$n(-)$ & 3.75 & 3.42 & 4.08 \\
\hline$\theta_{s}(-)$ & 0.375 & - & - \\
$\theta_{r}(-)$ & 0.033 & - & - \\
\hline$k_{s}\left(\mathrm{~m} \mathrm{~s}^{-1}\right)$ & $1.2 \mathrm{e}-2$ & - & - \\
$k_{s}\left(\mathrm{~cm} \mathrm{~min}^{-1}\right)$ & 72 & & \\
\hline
\end{tabular}

\begin{tabular}{l|l|l|l|l}
\hline Material & $\theta_{r}(-)$ & $\theta_{s}(-)$ & $\alpha\left(\mathrm{cm}^{-1}\right)$ & $n(-)$ \\
\hline METHA-sand & 0.0339 & 0.296 & 0.0418 & 2.12 \\
\hline $1 / 3$ gravel & 0.036 & 0.255 & 0.210 & 2.36 \\
\hline
\end{tabular}




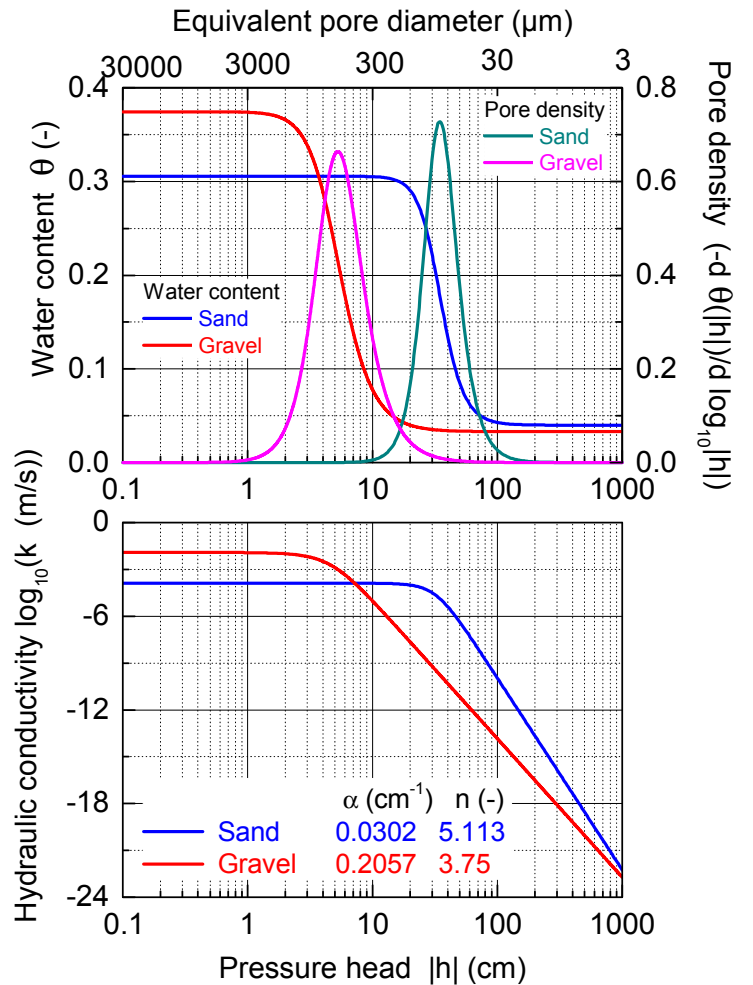

Fig. 4. Water content-pressure head functions, pore density distributions, and hydraulic conductivity-pressure head functions for the METHA-sand and 1/3 gravel using the van Genuchten-Mualem model.

Therefore, the Brooks-Corey parameters, including the residual and the saturated water contents, were also fitted to the water content-pressure head data using RETC (see Table 4). The values of the residual and the saturated water content differed from those determined for the van Genuchten-Mualem model. In the simulations with the Brooks-Corey model, the lower limit of the tension interval of the internal interpolation tables was set to $24 \mathrm{~cm}$, i.e., slightly higher than the bubbling pressure.
Scaling: The first set of simulations assumed homogeneous and isotropic materials. However, homogeneity is a concept that cannot be found in pure form in nature. Due to spatial heterogeneity, the breakthrough of the capillary barrier may occur in fingers that are self-reinforcing with increasing inflow rates. Therefore, stochastically distributed scaling factors were used to model spatial heterogeneity. The Miller-Miller similitude with default values as given in the HYDRUS user interface was selected, except for the standard deviation of $\log 10(y)$ of the hydraulic conductivity scaling factor, which, after some tests, was set to 0.125 .

HYDRUS version: The standard HYDRUS version assigns material properties to the nodes of the FE mesh. According to Heiberger (1996, p. 52), this approach does not allow for a sharp interface between two layers, but leads to an interface layer with alternating intermediate material properties. In the alternative HYDRUS version (Šimůnek, 2017), material properties are assigned directly to the FE elements, thus allowing abrupt textural changes and sharp interfaces between two layers.

Of the 16 possible combinations of the input setup ( 2 soil hydraulic property models, homogeneous vs heterogeneous, 2 HYDRUS versions, and 2 lower boundary conditions), 9 combinations were simulated. Seven combinations, among them six with a free drainage boundary condition, were not simulated because further insights were not expected from their results.

\section{RESULTS AND DISCUSSION \\ Comparison of measured and simulated outflow rates}

The results are depicted in Figs. 5 to 8. The dependence of measured and simulated outflow rates on the inflow rates is shown in Figs. 5 and 8 in the same manner. The slope 1:25 is in the left column, the slope 1:5 is in the right column, flow from the capillary layer is in the upper row and flow from the capillary block is in the lower row. Symbols mark simulated stationary periods. Every pair of simulated outflow rates from the capillary layer and the capillary block for the same inflow rate should sum up to the inflow rate (steady state). Actually, in most cases the simulated outflow rates summed up to 99.8 to $100.0 \%$ of the inflow rates. Sometimes, the percentage was a

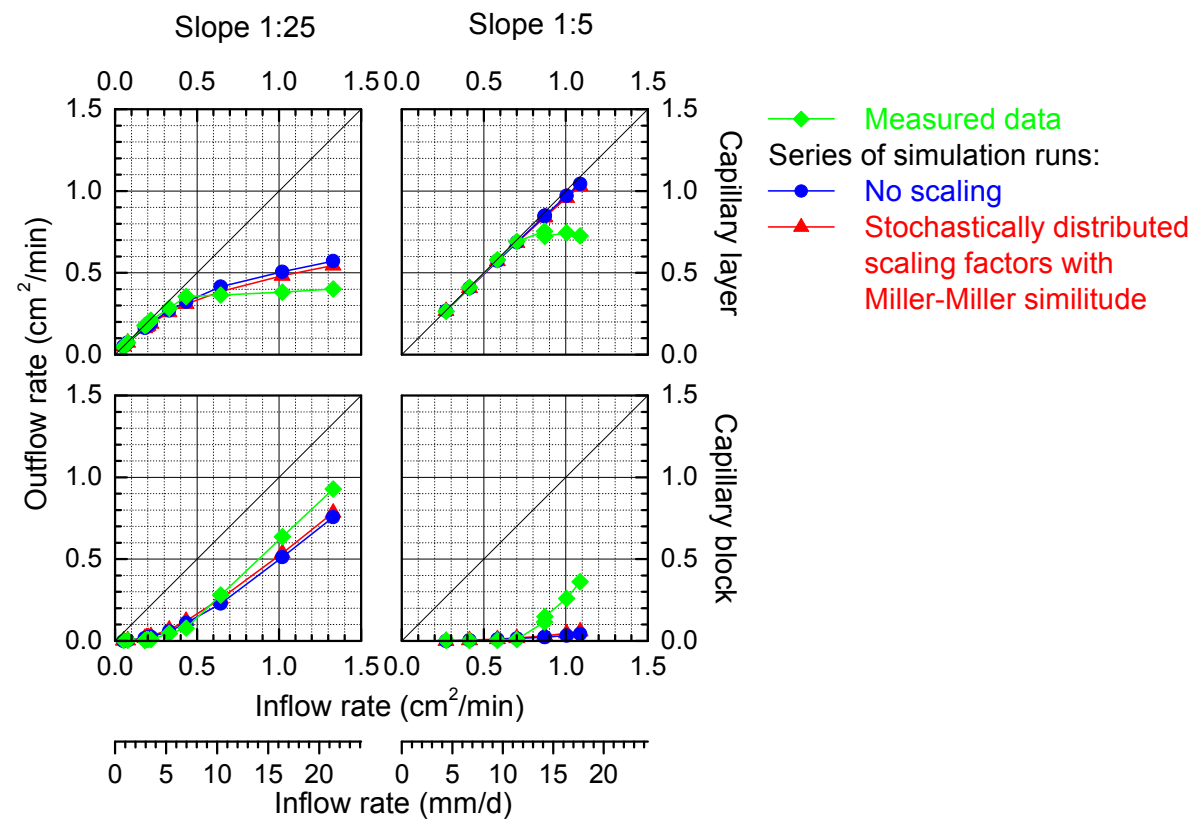

Fig. 5. Comparisons of measured and simulated outflow rates from a capillary layer and a capillary block dependent on the inflow rates for the model setup with the van Genuchten-Mualem model, a standard HYDRUS version, and a seepage face. 

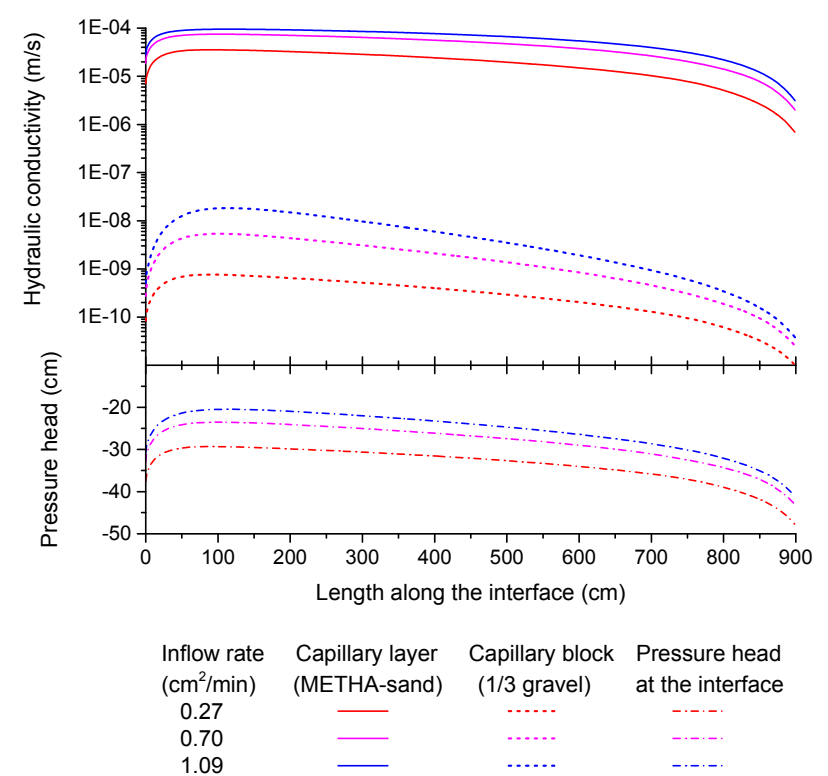

Fig. 6. The pressure heads along the interface between the capillary layer and the capillary block, as well as the corresponding hydraulic conductivities in the two materials calculated using the van Genuchten-Mualem model. The results are for the model setup with the van Genuchten-Mualem model, no scaling, the standard HYDRUS version, a seepage face boundary condition, the 1:5 slope, and three inflow rates (the smallest, a medium, and the largest inflow rate). The length along the interface is directed from the bottom $(0 \mathrm{~cm})$ to the top $(900 \mathrm{~cm})$ of the capillary barrier.

bit smaller, namely for the flat slope 1:25 and the smallest inflow rate, or if a simulation run was aborted. In the latter case, the latest available stored result was evaluated. To simplify the interpretation of the results, the inflow rates in Figs. 5 and 8 are shown in the abstract simulation unit of $\mathrm{cm}^{2} / \mathrm{min}$ as well as in $\mathrm{mm} / \mathrm{d}$, which is commonly used for precipitation, evapotranspiration, and discharge.

The measured data show typical flow patterns (Fig. 5). At small inflow rates, almost all infiltration water moves laterally downward in the capillary layer along the interface and almost no outflow is measured from the capillary block. For the flat slope 1:25 and the first threshold of the inflow rate of approximately $4 \mathrm{~mm} / \mathrm{d}$, water starts breaking through the interface into the capillary block, leading to an increase in capillary block outflow. For the second threshold of the inflow rate of 7.0 $\mathrm{mm} / \mathrm{d}$, most of the additional water infiltrating into the capillary layer breaks through into the capillary block and the outflow rate from the capillary layer increases only slightly. For the steep slope 1:5, only one threshold can be identified. At this threshold of $11.4 \mathrm{~mm} / \mathrm{d}$, all additional water infiltrating into the capillary layer breaks through into the capillary block and the outflow rate from the capillary layer remains approximately constant. With respect to the efficiency of the capillary barrier in cover systems, the capillary layer outflow at the (second) threshold can be denoted as the 'lateral drainage capacity' of the capillary barrier (Steinert et al., 1997a). This characteristic is different from the 'diversion capacity' of Ross (1990) (see also Lacroix Vachon et al., 2015). The objective of the numerical simulations was to reproduce this flow pattern and to identify the threshold(s).

However, the simulated outflow rates show a different flow pattern with a smooth increase in the outflow rates from the capillary layer and the capillary block, without any visible thresholds. In the model setup with the van Genuchten-Mualem model, the standard HYDRUS version, and a seepage face (Fig. 5), HYDRUS reproduced the outflow rates at small to medium inflow rates well. However, especially for the steep slope 1:5 and high inflow rates, HYDRUS overestimated the outflow rates from the capillary layer and underestimated those from the capillary block. Thus, the model overestimated the efficiency of the capillary barrier just for those conditions (steep slopes) for which capillary barriers are to be used. Simulations performed in 1995 with the predecessor model SWMS_2D (Šimůnek et al., 1992) and modified values of the van Genuchten-Mualem parameters and the saturated hydraulic conductivities of Table 4 (among others $\alpha$ and $n$ of the 95\% confidence intervals) yielded smooth outflow patterns as well (Berger, 2017; Steinert et al., 1997a).

Fig. 6 illustrates the reason for the simulated smooth outflow pattern without visible thresholds for the 1:5 slope and the model setup with the van Genuchten-Mualem model, no scaling, the standard HYDRUS version, and a seepage face boundary condition. The hydraulic conductivities along the interface of the capillary barrier in the capillary layer and the capillary block differ by about 4 to 5 orders of magnitude. The ratio of the hydraulic conductivities of the capillary layer and the capillary block decreases with increasing inflow rates. However, for the largest inflow rate the hydraulic conductivity of the capillary layer material is still about 4 orders of magnitude larger than that of the capillary block material.

Fig. 5 also shows that the corresponding outflow rates simulated without scaling and with stochastically distributed scaling factors for the Miller-Miller similitude are close together. This result also holds for the model setup with the Brooks and Corey model, the standard HYDRUS version, and a seepage face. This means that if fingering occurs in the simulation (due to heterogeneity), it does not play as important a role as expected.

The simulation results with the alternative HYDRUS version indicate a more efficient capillary barrier, i.e., the outflow rates from the capillary layer were larger and those from the capillary block were smaller compared to those simulated using the

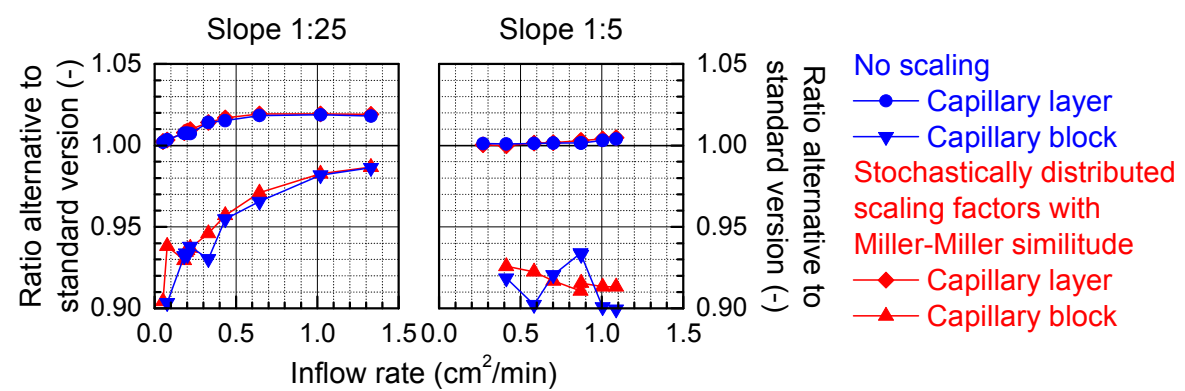

Fig. 7. A ratio of corresponding outflow rates from a capillary layer and a capillary block dependent on the inflow rates simulated by alternative and standard HYDRUS (2D/3D) versions for the model setup with the van Genuchten-Mualem model and a seepage face. 


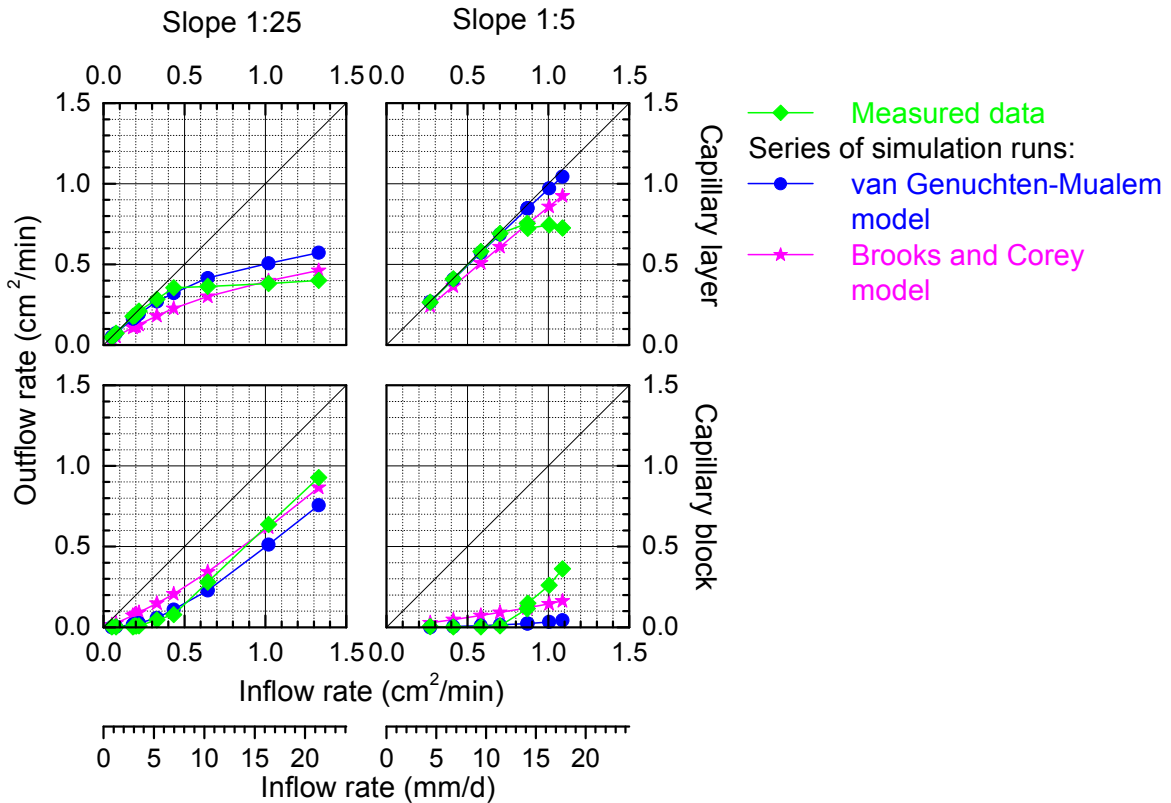

Fig. 8. Comparisons of measured and simulated outflow rates from a capillary layer and a capillary block for different inflow rates and slopes, and for a model setup with no scaling, a standard HYDRUS version, and a seepage face.

standard HYDRUS version (see Fig. 7 for the model setup with the van Genuchten-Mualem model and a seepage face). However, for the fine FE mesh used in these simulations, the impact of the alternative HYDRUS version is relatively small. While for the slope $1: 25$, the outflow rates from the capillary layer increased up to $2 \%$ compared to the standard HYDRUS version, for the steep slope $1: 5$, the differences were less than $1 \%$. The outflow rates from the capillary block simulating with the alternative HYDRUS version were between 90 and $99 \%$ of those simulated with the standard version. However, the base of these percentages is very small compared to the outflow rates from the capillary layer (the very small values may be one reason for the irregular, counter-intuitive 'up and down' of the ratios for the 1:5 slope in Fig. 7). Unpublished results of similar simulations with a much coarser FE mesh (i.e., 367 nodes and 785 elements) showed a much larger impact of the HYDRUS version. The alternative HYDRUS version produced outflow rates from the capillary layer up to $41 \%$ higher than the standard HYDRUS version. Obviously, the impact of how soil hydraulic properties are assigned, either to FE nodes (as in the standard HYDRUS version) or to FE elements (as in the alternative HYDRUS version) becomes smaller for a smaller FEsize. The outflow rates obtained with the alternative HYDRUS version matched the measured outflow rates worse than those obtained with the standard version. However, when using fine FE meshes the impact of the HYDRUS version can be neglected in this application because the differences to the results of the standard version are small.

For the model setup with no scaling, the standard HYDRUS version, and a seepage face, the HYDRUS model with the Brooks and Corey model predicted a less efficient capillary barrier with a larger breakthrough into the capillary block and smaller outflow rates from the capillary layer compared to the van Genuchten-Mualem model (Fig. 8). However, the model setup with the Brooks and Corey model also produced smooth outflow patterns without visible thresholds. Although the match between the simulated and measured data is not bad for the slope $1: 25$, the efficiency of the capillary barrier is significantly overestimated for the slope 1:5 and large inflow rates.

Replacing the seepage face lower boundary condition with the free drainage boundary condition had almost no impact on the outflow rates for the model setup with the van GenuchtenMualem model and no scaling. This remained true for both the standard and alternative HYDRUS versions. However, 22 out of the 38 simulation runs with free drainage aborted, which led to slightly irregular outflow patterns.

\section{Possible reasons for the mismatch between measured and simulated outflow rates}

Due to the systematic measurement and simulation results, the mismatch between measured and simulated outflow rates is very likely caused by systematic rather than random errors. There are three groups of possible reasons explaining the mismatch between measured and simulated outflow rates.

1) Errors in the empirical investigation

Although the 10-m tipping trough is a well-defined device, it is relatively large and thus there may be many sources of errors and uncertainties in the experiments. For example, the materials filling the tipping trough may be spatially heterogeneous because of the method of filling the device, or water flow may be impacted by variable temperatures in the lab. Furthermore, there may have been no stationary flow in the assumed stationary periods because of water redistribution inside of the tipping trough. Even so, the typical measured flow pattern with distinct threshold values of the inflow rates that indicates the efficiency of the capillary barrier and depends on the material combination and the slope is well confirmed (Steinert, 1999).

2) Errors in the application of the model

The simulation task, such as the shape of the tipping trough and the capillary barrier, is quite well defined. However, some material properties were not considered in the simulations due to missing measurement data. For example, hysteresis of the soil hydrological functions and the anisotropy of the hydraulic conductivity of used materials was not evaluated. Both materials (METHA-sand and 1/3 gravel) were technically pre-treated and therefore had a specific grain-size and pore-size distribution. This may be one reason why the parameterization of the van Genuchten-Mualem model for the soil hydrological functions was not unique (see point 3 below).

The spatial heterogeneity of material properties was modeled using scaling of soil hydraulic properties. If fingering plays an 

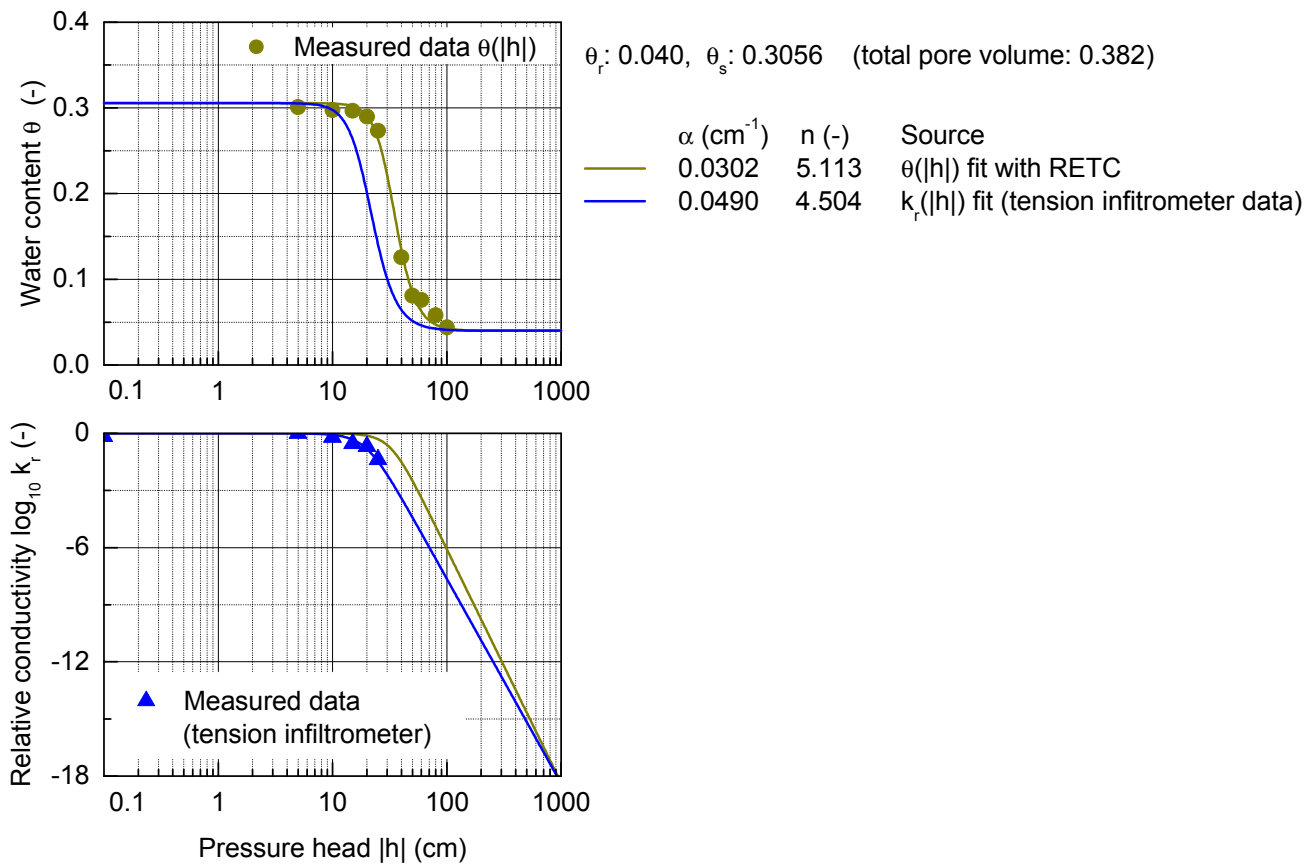

Fig. 9. Two fits of the van Genuchten-Mualem model to different measured data sets of the METHA-sand.

important role in flow across the interface of the capillary layer and capillary block, two-dimensional simulations are not sufficient to capture such phenomenon because they assume constant conditions in the third dimension. Fingers as separate three-dimensional entities require three-dimensional explicit representation.

3) Errors or unsuitable approaches in the model

This is a complex problem, which is in large part beyond the scope of this paper. For example, the van Genuchten-Mualem model (van Genuchten, 1980) may not be suitable to describe the soil hydraulic relationships of the technical pre-treated materials used in the capillary barrier. The fitting of the van Genuchten-Mualem model to two data sets for the METHAsand measured with different methods resulted in significantly different parameter values for $\alpha$ and $n$ (see Fig. 9). These data sets include water content-pressure head data from a pressure plate apparatus and unsaturated hydraulic conductivity data from tension infiltrometer measurements. Furthermore, to achieve a good fit for the water content-pressure head data, $\theta_{s}$ had to be set equal to only $80 \%$ of the total pore volume. The importance of the hydraulic parameters for the simulation results has already been emphasized by other authors (Barth, 2003; Kämpf et al., 2003).

None of the reasons mentioned in this brief discussion seem to be essential for explaining the mismatch between measured and simulated flow patterns of the capillary barrier. Thus, this problem unfortunately remains unsolved.

\section{CONCLUSIONS}

The model application described in this paper is quite simple. The shape of the tipping trough and of the capillary barrier inside is well defined, the two materials are quite well defined, and only stationary periods are simulated. The flow processes along and across the interface of the capillary layer and capillary block are critical for successful modeling of capillary barriers. The HYDRUS (2D/3D) model could not reproduce the measured outflow patterns and could not identify the threshold values indicating the efficiency of the capillary barrier. Possible sources of errors explaining the mismatch between measured and simulated outflow patterns were discussed. Errors could exist in the empirical investigation, the application of the model, or in the model itself. However, it is the author's opinion that the essential reason(s) for the mismatch between simulated and measured outflow rates could not yet be identified. To improve the results, further simulations could be performed to determine the soil hydraulic properties by inverse modeling for particular stationary periods.

According to the simulation results described in this paper and those of other authors (e.g., Barth, 2003; Kämpf et al., 2003), the two-dimensional models as HYDRUS (2D/3D) should currently not replace empirical investigations of tipping troughs or test fields for the dimensioning of capillary barriers.

Acknowledgments. The empirical investigation in the tipping trough and the simulations with SWMS_2D were funded by the German Federal Ministry for Education, Science, Research and Technology (BMBF) within the integrated research project 'Advanced Landfill Liner Systems' under the project number 1440 569A-39. The author thanks Dr. habil. Stefan Melchior and Prof. Dr. Günter Miehlich, who led the empirical investigation, and Dr. Bernd Steinert, Matthias Türk, Karin Burger and all involved staff members for their work. The author also thanks Prof. Jirka Šimůnek for providing the alternative HYDRUS (2D/3D) version.

\section{REFERENCES}

Barth, C., 2003. Die Wirksamkeit der Kapillarsperre als Deponieoberflächenabdichtung. Feldversuche auf der Deponie Bayreuth. [The efficiency of the capillary barrier as landfill sealing. Field experiments on the landfill Bayreuth.] PhD Thesis. University of Munich, Germany. (In German.)

Berger, K., 1999. Validation of the Hydrologic Evaluation of Landfill Performance (HELP) model for simulating the water balance of cover systems. Environmental Geology, 39, $11,1261-1274$.

Berger, K., 2017. Comparison and validation of SWMS 2D and 
HYDRUS (2D/3D) for capillary barriers using data of a $10-\mathrm{m}$ tipping trough. In: Proceedings Sixteenth International Waste Management and Landfill Symposium, 2-6 October 2017, S. Margherita di Pula, Cagliari, Italy. CISA Publisher, $10 \mathrm{p}$.

Heiberger, T.S., 1996. Simulating the effects of a capillary barrier using the two-dimensional variably saturated flow model SWMS_2D / HYDRUS-2D. Master thesis. Oregon State University, $124 \mathrm{p}$.

Holfelder, T., 2002. Temperaturbeeinflusste Transportprozesse in Kapillarsperren zur Oberflächenabdichtung von Deponien und Altlasten. [Temperature-affected transport processes in capillary barriers for the surface sealing of landfills and contaminated sites.] PhD Thesis. Technical University of Darmstadt, Germany. (In German.)

Jelinek, D., 1997. Die Kapillarsperre als Oberflächenbarriere für Deponien und Altlasten - Langzeitstudien und praktische Erfahrungen in Feldversuchen. [The capillary barrier as surface barrier for landfills and contaminated sites. - Long-term studies and practical experiences in field studies.] $\mathrm{PhD}$ Thesis. Technical University of Darmstadt, Germany. (In German.)

Kämpf, M., 2000. Fließprozesse in Kapillarsperren zur Oberflächenabdichtung von Deponien und Altlasten Grundlagen zur hydraulischen Bemessung. [Flow processes in capillary barriers for surface sealing of landfills and contaminated sites - Fundamentals for dimensioning.] $\mathrm{PhD}$ Thesis. Technical University of Darmstadt, Germany. (In German.)

Kämpf, M., Holfelder, T., Montenegro, H., 2003. Identification and parameterization of flow processes in artificial capillary barriers. Water Resources Research, 39, 10, 9 p.

Knepell, P.L., Arangno, D.C., 1993. Simulation Validation. A Confidence Assessment Methodology. IEEE Computer Society Press, Los Alamitos, CA.

Konikow, L.F., Bredehoeft, J.D., 1992. Ground-water models cannot be validated. Adv. Water Resour., 15, 75-83. Comment by de Marsily, G., Combes, P., Goblet, P., 1992. Adv. Water Resour., 15, 367-369. - Reply to Comment by J.D. Bredehoeft, Konikow, L.F., 1992. Adv. Water Resour., 15, 371-372.

Kung, K.-J.S., 1990. Preferential flow in a sandy vadose zone: 2. Mechanism and implications. Geoderma, 46, 1-3, 59-71.

Lacroix Vachon, B., Abdolahzadeh, A.M., Cabral, A.R., 2015. Predicting the diversion length of capillary barriers using steady state and transient state numerical modeling: case study of the Saint-Tite-des-Caps landfill final cover. Canadian Geotechnical Journal, 52, 2141-2148.

Melchior, S., 1993. Wasserhaushalt und Wirksamkeit mehrschichtiger Abdecksysteme für Deponien und Altlasten. [Water balance and efficiency of multi-layered cover systems for landfills and contaminated sites.] PhD Thesis. University of Hamburg, Germany, 330 p. (In German.)

Melchior, S., Sokollek, V., Berger, K., Vielhaber, B., Steinert, B., 2010. Results from 18 years of in situ performance testing of Landfill Cover Systems in Germany. Journal of Environmental Engineering, ASCE, 136, 8, 518-523.

Oldenburg, C.M., Pruess, K., 1993. On numerical modeling of capillary barriers. Water Resour. Res., 29, 4, 1045-1056.

Oreskes, N., Shrader-Frechette, K., Belitz, K., 1994. Verification, validation, and confirmation of numerical models in the Earth sciences. Science, 263, 641-646.

Pfeiffer, B., 2006. Vergleichende Untersuchungen von Kapillarsperren aus Natur- und Recyclingbaustoffmaterialien als Beitrag zur Deponieoberflächenabdichtung und Ressourcenschonung. [Comparative studies of capillary barriers from natural and recycling materials as a contribution for landfill sealing and preservation of resources.] PhD Thesis. University of Giessen, Germany. (In German.)

Radcliffe, D.E., Šimůnek, J., 2010. Soil Physics with HYDRUS. Modeling and Applications. CRC Press, Boca Raton, FL, $372 \mathrm{p}$.

Ross, B., 1990. The diversion capacity of capillary barriers. Water Resources Research, 26, 10, 2625-2629. (See also WRR, 27, 8, 2155-2157).

Šejna, M., Šimůnek, J., van Genuchten, M.Th., 2016. The HYDRUS Software Package for Simulating the Two- and Three-Dimensional Movement of Water, Heat, and Multiple Solutes in Variably-Saturated Porous Media. User Manual, Version 2.05. PC Progress, Prague, Czech Republic, 306 p.

Šimůnek, J., 2017. Alternative HYDRUS-2D code to allow definition of abrupt textural changes. Personal communication.

Šimůnek, J., Vogel, T., van Genuchten, M.T., 1992. The SWMS 2D code for simulating water flow and solute transport in two-dimensional variably saturated media. Vs. 1.1. Research Report 126. U.S. Salinity Lab., Riverside, CA, 169 p.

Šimůnek, J., van Genuchten, M.Th., Šejna, M., 2016. Recent developments and applications of the HYDRUS computer software packages. Vadose Zone Journal, 15, 7, 25 p. DOI: 10.2136/vzj2016.04.0033.

Steinert, B., 1999. Kapillarsperren für die Oberflächenabdichtung von Deponien und Altlasten - Bodenphysikalische Grundlagen und Kipprinnenuntersuchungen. [Capillary barriers for the surface lining of landfills and contaminated sites. Soil physical fundamentals and tipping trough experiments.] $\mathrm{PhD}$ Thesis. University of Hamburg, Germany, 250 p. (In German.)

Steinert, B., Melchior, S., Burger, K., Berger, K., Türk, M., Miehlich, G., 1997a. Dimensionierung von Kapillarsperren zur Oberflächenabdichtung von Deponien und Altlasten. [Dimensioning of capillary barriers for the surface lining of landfills and contaminated sites.] Hamburger Bodenkundliche Arbeiten 32, 420 p. (In German.)

Steinert, B., Melchior, S., Burger, K., Berger, K., Türk, M., Miehlich, G., 1997b. Design of capillary barriers for capping of landfills and contaminated sites. In: August, H., Holzlöhner, U., Meggyes, T. (Eds.): Advanced Landfill Liner Systems. Th. Telford, London, pp. 286-301.

van Genuchten, M.Th., 1980. A closed-form equation for predicting the hydraulic conductivity of unsaturated soils. Soil Sci. Soc. Am. J., 44, 892-898.

van Genuchten, M.Th., Leij, F.J., Yates, S.R., 1991. The RETC Code for Quantifying the Hydraulic Functions of Unsaturated Soils. EPA Report No. 600/2-91/065. U.S. Salinity Laboratory, Riverside, California, $83 \mathrm{p}$.

von der Hude, K. N., 1999. Kapillarsperren als Oberflächenabdichtungen auf Deponien und Altlasten. Laborversuche und Bemessungsregeln. [Capillary barriers as surface sealing on landfills and contaminated sites. Laboratory experiments and dimensioning rules.] $\mathrm{PhD}$ Thesis. Technical University of Darmstadt, Germany. (In German.)

Yeh, T.-C.J., Guzman, A., Srivastava, R., Gagnard, P.E., 1994. Numerical simulation of the wicking effect in liner systems. Ground Water, 32, 1, 2-11.

Zischak, R., 1997. Alternatives Oberflächenabdichtungssystem "Verstärkte mineralische Abdichtung mit untenliegender Kapillarsperre". [Alternative cover system "Strengthened cohesive liner with capillary barrier below".] $\mathrm{PhD}$ Thesis. University of Karlsruhe, Germany. (In German.)

Received 28 June 2017 Accepted 22 December 2017 